Hemotherapy in the Norwegian Armed Forces Hans Erik Heier, ${ }^{1}$ Knut Ole Sundnes, ${ }^{2}$

Johan Pillgram-Larsen ${ }^{3}$

1. Olso University Hospital, Ullevaal, N-0407, Norway; Norwegian Armed Forces Medical Services N-2058 Sessvollmoen, Norway

2. Norwegian Armed Forces Medical Services, N-2058 Sessvollmoen, Norway

3. Norwegian Armed Forces Medical Services, N-2058 Sessvollmoen, Norway; Oslo University Hospital, Ullevaal, N0407, Norway

For decades, standards for blood transfusion in the field have shifted due to logistical constraints combined with identified problems regarding the transmission of infections, immunizations, and depletion coagulopathy. A directive for hemotherapy in the Norwegian Armed Forces was issued in 2008 to ensure that military transfusion standards are comparable to civilian standards.

Blood products, supplied from Norway, only are given at surgical installations. Solvent-detergent-treated fresh frozen plasma $\left(\mathrm{Octaplas}^{\circledast}\right)$ blood group $\mathrm{AB}$, kept at $-20^{\circ} \mathrm{C}$ ), is used to secure concentrations of coagulation factors. Thawing takes 20 minutes. Freeze-dried fibrinogen is optional. Recombinant coagulation factor VIIa (NovoSeven) is available.

Leukocyte filtered erythrocyte concentrates of blood group $\mathrm{O}$ in SAGMAN solution, transported and kept at $4-8^{\circ} \mathrm{C}$, are used to secure adequate oxygen supply. Fresh whole blood (FWB), donated ad hoc by blood grouped personnel and pretested for transmissible diseases, is the only source of thrombocytes. Two units of blood group $\mathrm{O}$ can be given regardless of the recipient's $A B O$ group. If more are required, cross-matched units of the recipients own $A B O$ are preferred.

Hemostasis-promoting products start early, administrating SAGMAN and Octaplas ${ }^{\circledR}$ as close to a ratio of 1:1 as possible. Octaplas ${ }^{\circledR}$ is thawed immediately when the arrival of an acutely bleeding patient is announced. If bleeding remains out of control after 4 units of SAGMAN, NovoSeven is given ( 90 microgram $/ \mathrm{kg} /$ body weight, single dose), simultaneous FWB donations should be initiated.

Fresh whole blood contains leukocytes, which may induce transfusion-associated lung injury (TRALI), transmit viral genomes, and induce immunization against HLA antigens. As all European nations comply with the European Blood Directive, European allies might supply blood products to each other when needed, taking advantage of, for example, the Dutch and the British system for the supply of active thrombocytes.

Keywords: fresh whole blood, hemotherapy; transfusion standards Prebosp Disast Med 2010;25(5):s100

\section{Lessons Learned from Terrorist Attacks}

G.V. Kipor; S.F. Goncharov; V.I. Shabanov

All-Russian Center for Disaster Medicine "Zaschita"

The Disaster Medicine Center, "Zaschita", is a chief coordinating center of the Health Ministry with the general goal of management and medical relief delivery in response to emergencies. The objective of this study is an analysis of all Disaster Medicine Center activities in complex emergencies and in medical relief delivery in terrorist attacks.
Medical staff of the Russian Disaster Medicine Service has responded to emergencies complicated by local military conflicts and by terrorist attacks. The absence of sufficient information, time necessary for deployment of a hospital, and decision-making on the upper level of management complicated the delivery of emergency medical care to the affected, injured victims during the emergency events and their aftermath.

One of the specificities of major terrorist attacks is a total or partial destruction or insufficiency of local medical facilities (Chechen Republic, Budennovsc, Beslan, and Tschinvali). The mobilization and air transportation of medical products, medical staff, and mobile multi-profile hospitals are detailed during a limited period of time. The collaboration of Emercom is accentuated on-site. The field hospital deployment is prepared on-site by local facilities. The security procedures are accomplished by special teams of the Internal Affairs Ministry. The majority of the injured are evacuated to the nearest regional hospitals after being primary treated on-site. The mechanisms, schemes, and procedures of air evacuation are analyzed.

A probable scenario of the situation in progress is to be the base of the response plan for immediate medical care delivery. The disaster response plan is to be prepared for any potential conflict or terrorist attack.

Keywords: lessons learned; Russia; terrorist attack Prehosp Disast Med 2010;25(5):s100

Psycho-Physiological Approach in Health Evaluation and Certification

Gennady V. Kipor

All-Russian Centre for Disaster Medicine "Zaschita"

Introduction: The selection and training of medical staff preparedness for the accomplishment field activities in emergencies requires a set of quantitative methods. The complex psycho-physiological approach requires the application of tools for the selection and preparedness at the psychological and professional levels. The goal of this study is to introduce into the original system of the computer instruments for the staff selection procedure, a battery of new methods for staff mental preparedness.

Methods: A battery of instrumented, quantitative evaluation methods is proposed for the study and use in laboratory and field conditions for emergency medical staff preparedness and psychological support. The methods are underlined by complicated, bilateral, sensorial reactions in modeled conditions of ipsi- and contra-lateral visual deprivation and conditioned environment on a computer screen. In the conditions of the experiment, the mechanisms of integrative factors regulating the characteristics of hemispheres asymmetry are evaluated and managed as a result of the specific procedures of influence. The conditions of selection and ultimate correction, if necessary, are determined as a result of preliminary professional preparedness and initial mental status. The methods battery is completely objective based on the quantitative criteria. The selection procedure dos not include any subjective evaluation step or any questionnaire.

Conclusions: The method battery is registered in the National Register of Patents and Inventions. The results 